\title{
Mecanismos alternativos de transmissão do Trypanosoma cruzi no Brasil e sugestões para sua prevenção
}

\section{Alternative transmission mechanisms of Trypanosoma cruzi in Brazil and proposals for their prevention}

\author{
João Carlos Pinto Dias ${ }^{1}$, Vicente Amato Neto ${ }^{2,3}$ e Expedito José de Albuquerque Luna ${ }^{2}$
}

\begin{abstract}
RESUMO
Introdução: Com o avanço no controle da transmissão vetorial e por transfusão sanguínea da doença de Chagas, as formas alternativas de transmissão ganharam relevância. Este artigo de opinião discute a importância de cada uma dessas modalidades e as medidas para sua prevenção. Métodos: Foi realizada uma revisão bibliográfica sobre os mecanismos de transmissão do Trypanosoma cruzi através de modalidades alternativas, vigentes no Brasil, e as possibilidades de sua prevenção. Foram consultadas as bases de dados PubMed e BVS. Resultados: Foram identificadas 25 publicações que discutiam as modalidades alternativas de transmissão da doença de Chagas. Conclusões: A transmissão oral, pela ingestão de alimentos contaminados, tem sido o modo de transmissão predominante no Brasil nos últimos anos. Os demais modos alternativos de transmissão são de ocorrência menos frequente. É importante conhecer essas ocorrências, sobretudo agora que a veiculação vetorial do parasita está controlada. Conforme os conhecimentos atuais foram apresentadas medidas preventivas, de acordo com cada uma das situações consideradas.
\end{abstract}

Palavras-chaves: Doença de Chagas. Transmissão do Trypanosoma cruzi. Modalidades alternativas. Prevenção.

\begin{abstract}
Introduction: Following advances in the control of vector and blood transfusion transmission of Chagas disease, alternative mechanisms of transmission have become more relevant. This article discusses the importance of each one of these alternative mechanisms and the measures to prevent them. Methods: A review was conducted of the scientific literature concerning alternative transmission mechanisms of Trypanosoma cruzi occurring in Brazil and the measures to prevent them. PubMed and BVS databases were consulted. Results: Twenty-five publications describing alternative mechanisms of transmission of Chagas disease were identified. Conclusions: Oral transmission, through ingestion of contaminated food items has been the most frequent mode of transmission in Brazil in recent years. Other alternative mechanisms of transmission occur less frequently. It is important to understand these occurrences, especially now that vector transmission of the parasite is under control. Preventive measures have been presented, according to each of the situations considered, in line with current knowledge.
\end{abstract}

Keywords: Chagas' disease. Trypanosoma cruzi transmission. Alternative mechanisms. Prevention.

1. Centro de Pesquisas René Rachou, Fundação Oswaldo Cruz, Belo Horizonte, MG. 2. Instituto de Medicina Tropical de São Paulo, Universidade de São Paulo, São Paulo, SP. 3. Laboratório de Investigação Médica - Parasitologia, Hospital das Clínicas, Faculdade de Medicina, Universidade de São Paulo, São Paulo, SP.

Endereço para correspondência: Prof. João Carlos Pinto Dias. CPqRR/FIOCRUZ. Av. Augusto de Lima 1715, 30190-002 Belo Horizonte, MG.

Tel: 5531 3295-3566

e-mail: jcpdias@cpqrr.fiocruz.br

Recebido para publicação em 22/01/2010

Aceito em 11/01/2011

\section{INTRODUÇÃO}

As formas básicas de transmissão da doença de Chagas humana (DCH) correspondem à transmissão pelo vetor e pela transfusão de sangue. Consideram-se alternativas as demais vias descritas como a oral, a acidental, a congênita e a por transplantes de órgãos. São entendidas como excepcionais ou hipotéticas outras possibilidades, como por via sexual, por contaminação através de outros vetores e por outras práticas (juras de amor, uso comunitário de drogas injetáveis $)^{1,2}$. Com os avanços no controle dos vetores domiciliares e rigorosa seleção de doadores de sangue em toda a área endêmica, as vias alternativas cresceram de importância. Inclusive, pelos fenômenos de globalização e migrações internacionais, têm oportunizado casos novos de $\mathrm{DCH}$ em países não endêmicos ${ }^{3-7}$. $\mathrm{Na}$ evolução da luta antichagásica no Brasil, após os trabalhos pioneiros de Emmanuel Dias e Pedreira de Freitas, nos anos 1940 e 1950, foram priorizadas as ações químicas contra o vetor domiciliado, em especial, a partir dos anos 1960. A melhora habitacional nunca deslanchou como programa nacional, seja pelos custos, seja pela priorização do modelo desenvolvimentista urbano industrial, em detrimento de programas sociais rurais ${ }^{8}$. A partir dos anos 1980, foi implementado, progressivamente, o controle de Bancos de Sangue ${ }^{8,9}$.

As demais formas de transmissão não foram consideradas prioritárias para os programas governamentais no Brasil, embora estudadas em sua ocorrência e pesquisadas algumas possibilidades de controle. Nesta pequena revisão, pretende-se discutir a importância e as perspectivas de prevenção dessas modalidades alternativas e da via congênita, no contexto dos achados e dos desdobramentos do II Inquérito Nacional de Prevalência, recém-terminado em nosso País. 


\section{TRANSMISSÃO CONGÊNITA OU VERTICAL}

Conforme o Consenso Brasileiro em Doença de Chagas $(\mathrm{CBCD})^{10}$ e o Colóquio Internacional sobre Infecção Congênita ${ }^{11}$, realizado na Bolívia, ambos publicados em 2005, a ocorrência de transmissão congênita (TC) ou Vertical é variável nas áreas endêmicas, dependendo basicamente do número de gestantes infectadas pelo Trypanosoma cruzi e de outros fatores ainda não bem conhecidos.

Em nosso País, o risco de TC em gestantes infectadas oscila em torno de $1 \%$, ampliando-se esta proporção para $4 \%$ e até $12 \%$ em outras áreas latino-americanas (CBDC). Sua incidência tende francamente à redução nas áreas de controle vetorial e transfusional implementados, pela redução progressiva da prevalência da infecção pelo Trypanosoma cruzi entre mulheres em idade fértil. Por exemplo, dados bem controlados em Bambuí, Minas Gerais, mostraram prevalência acima de 30\% das mulheres na década de 1950, baixando para 9\% nos anos 1970 e para menos de 1\% em 2006. Dados para Minas Gerais, em 2004, registraram 1\% de infecção entre 65 mil puérperas examinadas. Em paralelo, o corrente inquérito nacional entre menores de 5 anos, com mais de 100 mil amostras colhidas no Brasil, está demonstrando taxa de infecção infantil abaixo de $0,02 \%$, com porcentagem de TC aparentemente mais expressiva no Rio Grande do Sul (dados preliminares).

A definição de caso congênito, conforme o CBDC considera basicamente as crianças nascidas de mães infectadas, com a confirmação do parasita no sangue do recém-nascido e/ou a detecção de anticorpos não maternos na criança após os seis ou sete meses de idade, desde que excluídos outros mecanismos de transmissão.

Clinicamente, a experiência acumulada nos diversos estudos mostra que mais de $70 \%$ das crianças com TC são normais e assintomáticas. Um resíduo nunca maior que $10 \%$ apresentará clínica florida e potencialmente grave, com quadro febril, hepatoesplenomegalia, miocardite, meningo-encefalite ou prematuridade ${ }^{6}$. Esses casos têm especial importância pelo risco concreto de morte, devendo ser prontamente diagnosticados e tratados. Para tanto, há consenso que frente a tais quadros em recém-nascidos, os pediatras pensem em $\mathrm{DCH}$ em áreas endêmicas, assim com diante de mães com antecedentes ou clínica sugestivos de infecção. Quanto ao diagnóstico, as melhores experiências em pesquisa direta do parasita têm sido através do método de micro-hematócrito. PCR, xenodiagnóstico e hemocultura, quando disponíveis, têm boa sensibilidade, mas não significam definitivamente infecção aguda nem transmissão congenita ${ }^{12,13}$. É consenso que a DCH congênita é muito vulnerável ao tratamento específico com as drogas hoje disponíveis (nifurtimox e benzonidazol) com cura acima de $90 \%$ dos tratados e com mínimos efeitos colaterais. Os pacientes tratados e seguidos por muitos anos mostraram boa resposta terapêutica e nenhuma sequela clínica ou imunológica da infecção a longo prazo ${ }^{12,13}$.

O diagnóstico da $\mathrm{DCH}$ congênita faz-se por métodos parasitológicos e sorológicos como entendido no conceito citado de definição de caso. Na circunstância de suspeita clínica forte, em recémnascidos de mulher infectada, recomenda-se insistir na busca direta do parasita, repetindo os exames varias vezes ao dia, em dias seguidos. Emprega-se também métodos parasitológicos indiretos, como a hemocultura e o xenodiagnóstico. Também se sugere a PCR ${ }^{12,13}$.

A prevenção da $\mathrm{DCH}$ congênita se resume na detecção do caso e seu tratamento específico, o mais precocemente possível.
Idealmente, o melhor é começar ainda na gravidez, através de provas sorológicas em gestantes com suspeita clínica ou epidemiológica. Os recém-nascidos das mães infectadas seriam pesquisados ao nascer com exames parasitológicos, tratando-se imediatamente os que resultassem positivos. Sendo negativos parasitologicamente fazer sorologia convencional aos sete ou oito meses de vida (quando desaparecem os anticorpos IgG maternos), tratando imediatamente os que forem positivos. Em alguns países, como Uruguai, Paraguai e partes da Argentina há screening sorológico de rotina em pré-natal. No Brasil, não há este procedimento como programa nacional, embora entidades como a Associação de Pais e Amigos dos Excepcionais (APAE) o realizem em Mato Grosso do Sul e Goiás. Em Minas Gerais, foram feitas duas investigações estaduais mediante sorologia para $\mathrm{DCH}$ no conhecido teste do pezinho, mostrando viabilidade técnica e exequibilidade. Nesta experiência, as crianças soropositivas foram novamente estudadas aos sete meses de vida, revelando mínima incidência de TC e sendo tratadas aquelas poucas que permaneceram positivas. Simplificando mais ainda, apenas o exame sorológico convencional aos sete meses de idade já seria altamente oportuno em áreas endêmicas e/ou situações de suspeição clínica e epidemiologica ${ }^{1,2,12}$. Nesta estratégia, os casos de maior suspeição clínica, ao nascer, seriam apenas estes, examinados exaustivamente por técnicas parasitológicas, acrescentando-se PCR e, se disponível, exame sorológico com proteína reconhecida por pacientes na fase aguda (shed acute phase antigene - SAPA), que marca mais precocemente a transmissão congênita. Em negativos, persistindo a dúvida, o tratamento específico de prova pode ser considerado ${ }^{2,12}$.

\section{TRANSMISSÃO ACIDENTAL DO TRYPANOSOMA CRUZI AO HOMEM}

Na década de 1980, houve contabilização de mais de 50 episódios, numa listagem pessoal informada por vários serviços no Brasil e exterior ${ }^{14,15}$. Julgava-se que eram muito mais, pois o evento pode ocorrer em variadas circunstâncias e muitas vezes passam despercebido ou não diagnosticado. Por outro lado, geralmente não há interesse em divulgação, pelo fato de significar insegurança, desaparelhamento ou inaptidão técnica do serviço ou pesquisador em questão ${ }^{1,16}$. Por outro lado, compreensivelmente, também o próprio acidentado pode ocultar ou negar a ocorrência do acidente, assim como é bastante comum uma fase aguda clinicamente pouco expressiva ou mesmo não aparente, problematizando a suspeição clínica e o próprio diagnóstico ${ }^{1}$. Os acidentes têm ocorrido nas mais diversas situações, seja em laboratórios de triatomíneos, seja na captura do vetor em áreas endêmicas, ou em trabalhos experimentais com mamíferos infectados, culturas ou em aerossóis de materiais infectados. Também há relatos de contaminação cirúrgica a partir de pacientes agudos, alem de deficiências de segurança no transporte de materiais infectados ${ }^{1,2,14,15}$. Os fatores de risco passam por desconhecimento, desatenção, falta ou mal uso de equipamentos de proteção individual, instalações e equipamentos inadequados, iluminação deficiente, falta de capacitação ou participação de outros motivos facilitadores ${ }^{1}$.

A prevenção desta via de transmissão passa por uma instância primária (antes da ocorrência) e outra secundária (prevenção do dano após o fato acontecido). Como não existe vacina, um estratagema usado por alguns chefes de pesquisa tem sido, quando possível, empregar e treinar técnicos já infectados pelo Trypanosoma cruzi. Em caráter ainda primário, é fundamental adotar as medidas 
universais de biossegurança com a configuração adequada e rigorosa do ambiente de trabalho com o parasita, assim como dispor de equipamentos de trabalho e proteção individual apropriados (luvas, máscara, óculos, mangas largas), bem como o cumprimento de rotinas preferencialmente descritas em procedimentos operacionais padronizados. Treinamento rigoroso de pessoal é indispensável, seja para técnicos, seja para iniciantes em pesquisas ${ }^{1}$. É muito pertinente que todo técnico a ser envolvido com o parasita faça um teste sorológico ao começo de sua atividade, para oportunas comparações, em eventuais acidentes, pois, por muitas vezes, o diagnóstico de fase aguda só se locupleta mediante viragem sorologica ${ }^{16}$.

A prevenção secundária apresenta caráter bastante prático e bem consensuado. Ocorrido um evento com suspeita de risco de transmissão, uma série de providências deve ser desencadeada: a) se houve ferimento ou contaminação (externa ou ocular), proceder à pronta desinfecção local com álcool, mertiolate ou nitrato de prata; b) colher sorologia de controle; c) iniciar prontamente tratamento específico com benzonidazol ou nifurtimox nas doses habituais, por dez dias. Após um mês, repetir a sorologia convencional. Se o primeiro exame foi negativo e neste positivo, considerar que houve transmissão e reiniciar o tratamento específico, agora em 60 dias. Segundo o CBDC, acidentes com alta carga parasitária devem ser tratados por um período de 30 dias. Em situações de mínimo risco, como com sangue de paciente na fase crônica, a profilaxia medicamentosa não está indicada, recomenda-se a monitorização sorológica.

Todo acidente e/ou ocorrência de transmissão acidental deve ser comunicado à comissão interna de biossegurança e às autoridades sanitárias, assim ensejando investigação do caso e avaliação com correção, dos fatores de risco ${ }^{10}$.

\section{TRANSMISSÃO POR TRANSPLANTE DE ÓRGÃOS}

Quando considerada a infecção pelo Trypanosoma cruzi, no contexto dos transplantes de órgãos, duas situações devem ser levadas em conta. Pode haver transmissão a partir do doador com $\mathrm{DCH}$ ou é viável reativação da parasitemia se o receptor está previamente infectado. A veiculação do parasita de doador infectado já foi documentada em transplantes de coração, fígado, medula óssea, pâncreas e rim, a partir de doador vivo, com morte cerebral ou eventualmente cadáver ${ }^{1,2}$. Os primeiros relatos de ocorrência de transmissão da doença de Chagas datam do início da década de 1980, especialmente através de transplante de rim $^{17}$.

A conduta básica a ser considerada nesta modalidade de transmissão tem por princípio o diagnóstico da infecção no doador e no receptor, através de sorologia convencional bem conduzida e realizada por meio de duas técnicas diferentes, de alta sensibilidade e especificidade. $O$ transplante de órgãos geralmente é procedimento prioritário como intervenção médica, cabendo judiciosa avaliação de sua realização, tanto em caso de doador quanto de receptor infectado. O ideal é não realizá-lo na situação de doador infectado e receptor suscetível; porém, via de regra, isto é difícil por questões de emergência clínica, de histocompatibilidade e disponibilidade de órgãos. Semelhantemente, a necessidade de um transplante para receptor infectado geralmente é razão mais forte que o risco ou conseqüências de reativação no pós-operatórioº .
Assim, consideradas as diferentes combinações de infecção e suscetibilidade, os aspectos de prevenção da $\mathrm{DCH}$ frente ao transplante de órgãos, poderiam resumir-se em: antes da cirurgia testar sorologicamente doador e receptor, considerando as possibilidades a seguir detalhadas: a) doador negativo e receptor negativo: nada a fazer quanto à $\mathrm{DCH}$; b) doador negativo e receptor positivo: basicamente atenção médico-laboratorial ao receptor no pós-operatorio para detecção de eventual reativação devida à imunossupressão. Em ocorrendo, tratar o paciente como em etapa aguda, assim minimizando os riscos de cardite aguda e/ ou meningoencefalite; c) doador positivo e receptor positivo: agir como a segunda alternativa; d) doador positivo e receptor negativo: é o caso mais importante, de ocorrência relativamente frequente, em particular nos transplantes renais. Geralmente, a necessidade do transplante é de motivação prioritária e o ato cirúrgico deve ser realizado, não se descartando o doador. Assim, indicada a cirurgia, e de acordo com a experiência existente, há duas alternativas: pode-se tratar o doador com imidazólico por dez dias prévios à operação (para baixar a parasitemia), profilaticamente o receptor utilizando o mesmo tipo de fármaco, nos dez dias subsequentes à mesma, para prevenir a instalação do parasita; pode-se monitorar o receptor clínico, parasita (hemocultivos e exames diretos) e solorogicamente (provas sorológicas aos 15 e 30 dias), iniciando o tratamento específico, se houver parasitemia detectável ou conversão sorológica.

\section{TRANSMISSÃO ORAL E POR LEITE MATERNO}

A transmissão da DCH por via oral é considerada mecanismo primário, mormente no ciclo silvestre da tripanossomiase. No Brasil, já fora aventada desde os anos 1920, através de modelos experimentais, sendo identificados os primeiros casos de grande probabilidade na década de 1960, no Rio Grande do Sul. Posteriormente, surtos muito prováveis de transmissão oral foram detectados no Pará, na Paraíba, em áreas amazônicas, em Santa Catarina, na Bahia e no Ceará, 18-20. Em outros países, houve surtos no México e na Venezuela, mais recentemente ${ }^{1,2}$. Muitos estudos experimentais demonstraram a viabilidade da transmissão oral em vários modelos animais ${ }^{16}$.

As seguintes possibilidades devem ser aventadas em relação ao mecanismo de transmissão oral na $\mathrm{DCH}^{1,16}$ : a) ingestão de leite materno, de mãe infectada (o parasita pode vir da própria glândula ou contaminar o leite em casos de sangramento mamilar); b) ingestão de sangue de mamífero infectado; c) ingestão de carne mal cozida de mamíferos infectados e, especialmente, de reservatórios silvestres; d) ingestão de suspensão de Trypanosoma cruzi em pipetas (acidente de laboratório); e) ingestão de alimentos ou bebidas contaminados com fezes ou urina de triatomíneos infectados por Trypanosoma cruzi; f) ingestão de alimentos ou bebidas contaminas com urina ou secreção para-anal de marsupiais infectados por Trypanosoma cruzi.

O quadro clínico é variado, sem lesões de porta de entrada, ocorrendo febre, fenômenos de irritação gástrica, dores abdominais, vômitos, melenas e icterícia em muitos casos. Sobrevêm com o tempo, em casos mais graves, cardiopatia aguda e sinais de irritação meníngea. A letalidade nos casos amazônicos (os mais numerosos) pode chegar a $5 \%{ }^{21-24}$. Diferentemente da via vetorial, os casos até aqui detectados estão em todos os grupos etários, indiscriminadamente. Na suspeita de transmissão oral, há que descartarem-se os mecanismos vetorial, congênito, transfusional/transplante e acidental. Mais da metade dos 
casos contabilizados apresenta a característica de surtos familiares ou comunitários com adoecimento em dias próximos e uma fonte comum referente a um evento alimentar, em um mesmo lugar ${ }^{1,16}$. O tratamento é o clássico da forma aguda, cuidando-se adicionalmente de possíveis hemorragias digestivas.

A prevenção da transmissão oral é relativamente difícil, dado o caráter aleatório e inesperado de seu acontecimento. Medidas gerais de higiene e boa seleção alimentar impõem, assim como a boa cocção de carnes silvestres de áreas endêmicas. No caso de alimentos produzidos artesanalmente em áreas com triatomíneos, normas de boa cocção e/ ou pasteurização tornam-se essenciais. Conforme a epidemiologia desses casos nos curtos investigados, a ocorrência de outros casos na sequência de um primeiro (caso índice) é acometimento bastante frequente. Assim, a busca ativa de contatos é imprescindível, para delimitação do surto e da oportunização de tratamento específico.

A pasteurização da pasta de açaí vem sendo adotada para o produto exportado da Amazônia para outras regiões do Brasil e para o exterior. A adoção de boas práticas de higiene alimentar, no consumo de pequena escala e doméstico minimiza os riscos de transmissão?.

Quanto ao leite materno, há que cuidar-se para que este assunto não seja propalado indevidamente, provocando resistência das mães em amamentar. Sua ocorrência é verdadeiramente excepcional e os pouquíssimos casos suspeitos envolveram mulheres com sangramento mamilar. Assim, sugere-se desaconselhar por algum tempo a amamentação apenas em mulheres em fase aguda ou estado de reativação da esquizotripanose (alta parasitemia) ou infectadas crônicas que apresentem rachaduras ou sangramento nos mamilos e aréolas.

\section{OUTRAS SITUAÇÕES EXCEPCIONAIS DE TRANSMISSÃO}

Na história da evolução dos conhecimentos sobre a $\mathrm{DCH}$, várias hipóteses ou possibilidade de transmissão têm sido aventadas, todos de acontecimento improvável e caráter excepcional ${ }^{1,8,16}$. Nessas hipóteses, envolvem-se situações incomuns como vetores alternativos, comportamentos humanos esdrúxulos e circunstâncias excepcionais de localização do parasita, várias delas com respaldo experimental. Como denominador comum, estará quase sempre uma grande concentração do parasita no ambiente de ocorrência, no mais das vezes envolvendo o triatomíneo vetor e/ou uma alta parasitemia em humanos ou reservatórios, fatos esses que podem orientar eventuais ações preventivas. Conforme revisão anterior é viável apontar as situações adiante experimentadas ${ }^{1,2}$.

\section{Transmissão pela picada de um triatomíneo}

Aventada pelo próprio Chagas, inicialmente. Não há colonização das glândulas salivares do vetor, pelo parasita. Sucederia de maneira excepcional em virtude de regurgitação de conteúdo estomacal do inseto contaminado, durante a picada, ou se a probóscida do vetor estiver contaminada por fezes infectadas dele mesmo ou de outro vetor. A prevenção lógica é a eliminação de triatomíneos no âmbito domiciliar, por via química e ordenamento do ambiente.

Contato do indivíduo suscetível com fezes contendo o Trypanosoma cruzi

Situação plausível em acidentes de laboratório, capturas de triatomíneos e contatos com paredes, objetos ou anexos domiciliares de vivendas infestadas, onde abundam dejeções do inseto, mormente em casos de elevada infestação. A permanência do parasita nessas fezes é viável por algum tempo (geralmente minutos), enquanto não ressecam. A transmissão dependerá do contato com mucosas íntegras ou pele lesada. A prevenção também é pelo controle do vetor em unidades domiciliares, higiene ambiental e pronta desinfecção do local de contato, quando percebido. Para capturas e manejo do vetor, são indicados cuidados e equipamentos de proteção individual.

\section{Picada ou contato com outros artrópodes}

Semelhantemente ao caso da picada de triatomíneos, basicamente envolvendo espécies hematófagas de insetos (culíneos, flebotomíneos, cimicídeos, pulgas e piolhos) ou de vários tipos de carrapatos, em situações raras, mas comprovadas experimentalmente ${ }^{16}$. Os mecanismos básicos envolveriam regurgitação após contaminação prévia em indivíduo com parasitemia alta, contaminação de probóscida e esmagamento ou ingestão de um artrópode destes, precariamente infectado pelo Trypanosoma cruzi. Em todos eles, o parasita pode permanecer algum tempo (horas) no segmento digestivo proximal, sem desenvolver seu ciclo natural. Em caso de moscas e baratas, tais insetos seriam apenas carreadores muito eventuais de fezes contaminadas de triatomíneos, em ambientes infestados, oportunizando transmissão oral ou por contato. A lógica da prevenção passa, naturalmente, pelo controle triatomínico, pela higiene ambiental e desinsetização de aposentos onde houver um caso agudo (ou reativado) de $\mathrm{DCH}$.

Transmissão através de secreção de glândulas anais de marsupiais

Foi assunto primeiramente estudado no Brasil, em Didelphis albiventris ou marsupialis (gambá) ${ }^{25}$. Em áreas endêmicas brasileiras, este marsupial sinantrópico mostra-se sempre com altas taxas de infecção natural (média de 30\%), sendo que dos infectados sistemicamente pelo menos $5 \%$ apresentam o parasita em suas glândulas anais ${ }^{1,25}$. O material destas glândulas pode ser expelido pelo gambá e contaminar alimentos ou diretamente um mamífero suscetível. Reproduzido em facilidade em laboratório, este mecanismo pode ter sido a causa do surto de DCH em Teutônia, Rio Grande do Sul, nos anos $1960^{1,16}$. É eventualidade difícil e a prevenção desta modalidade envolve o afastamento de gambás dos ecótopos artificiais, assim como cuidados no manejo desses animais. Acontecido o contato com a secreção, monitorar o paciente (sorológica e parasitologicamente), entrando com tratamento específico concomitante se o gambá estiver muito parasitado e se o contato com o material contaminante for em mucosas ou pelo lesada. De qualquer forma, realizar generosa desinfecção local, com álcool iodado ou solução similar.

\section{Transmissão por via sexual}

Trata-se de possibilidade remota, tendo sido conseguida experimentalmente: coito de cadelas com vagina inseminada com tripomastigotas, contaminando machos suscetíveis e infecção de cadelas ou roedores suscetíveis por via vaginal com sêmen infectado. No ser humano, há suspeita de contaminação de varões suscetíveis pelo coito com mulheres infectadas, durante a menstruação ${ }^{1}$. Essas possibilidades aumentam muito a partir de indivíduos com alta parasitemia (em fase aguda ou imunossuprimidos), devendo-se então recomendar abstinência sexual ${ }^{1}$.

\section{Outras possibilidades hipotéticas e ainda mais remotas}

Praticamente restritas a indivíduos de alta parasitemia. Tratamse de situações nunca comprovadas, imagináveis apenas em que sangue ou secreções contaminados poderiam entrar em contato com 
suscetíveis, por exemplo, através do uso comum de seringas e agulhas descartáveis, em juras de amor com trocas de sangue ou nos rituais macabros, comportamentos citados como ilustrações ${ }^{1}$.

Em síntese, os principais cuidados pertinentes aos mecanismos menos usuais de transmissão dizem respeito ao combate sistemático de triatomíneos além de outros insetos no intradomicílio, ao afastamento e aos cuidados no manejo de gambás ou outros reservatórios ao redobrado cuidado com o tratamento específico imediato de indivíduos com alta parasitemia, à boa higiene alimentar, havendo também monitoramento correto de recém-nascidos de mulheres infectadas ${ }^{1}$.

\section{CONFLITO DE INTERESSE}

Os autores declaram não haver nenhum tipo de conflito de interesse no desenvolvimento do estudo.

\section{REFERÊNCIAS}

1. Chieffi PP, Amato Neto V. Prevenção referente às modalidades alternativas de transmissão do Trypanosoma cruzi. São Paulo: Instituto de Medicina Tropical de São Paulo; 2000

2. Dias JCP, Macedo VO. Doença de Chagas. In: Coura JR, editor. Dinâmica das doenças infecciosas e parasitárias. Rio de Janeiro: Guanabara Koogan; 2005. p. 557-594.

3. Carlier Y, Dias JCP, Luqueti AO, Hontebeyrie M, Torrico F, Truyena C. Trypanosomiase américaine ou maladie de Chagas. In: Encyclopédie MedicoChirurgicale. Maladies Infectieuses. Editions Scientifiques et Médicales Elsevier. Paris: Masson; 2002. 8-505A-520a.

4. Dias JCP. O controle da doença de Chagas no Brasil. In: Silveira AC, editor. El control de la enfermedad de Chagas em los países Del Cono Sur de América. Historia de una iniciativa internacional 1991/2001. Uberaba: Organização Panamerica da Saúde. Faculdade de Medicina do Triângulo Mineiro; 2002. p. 146-250.

5. Miles MA, Yeo M, Gaunt MW. Epidemiology of American Trypanosomiasis. In: Maudlin I, Holmes PH, Miles MA, editores. The Trypanosomes. London: CABI Publishing; 2004. p. 243-251.

6. Moya PR, Moretti ERA. Doença de chagas congênita. In: Dias JCP, Coura JR, editores. Clínica e terapêutica da doença de Chagas. Um manual prático para o clínico geral. Rio de Janeiro: Fundação Oswaldo Cruz; 1997. p. 383-409.

7. World Health Organization. Control of Chagas disease. Second report of the WHO Expert Committee. World Health Organization Technical Report Series 905; 2002.

8. Dias JCP, Schofileld CJ. The evolution of Chagas disease (American trypanosomiasis) control after 90 years since Carlos Chagas Discovery. Mem Inst Oswaldo Cruz 1999; 94 (supl I):103-121.

9. Organização Panamericana da Saúde. Doença de Chagas: guia para vigilância, prevenção, controle e manejo clínico da doença de Chagas aguda transmitida por alimentos. Série Manuais Técnicos - n. ${ }^{\circ}$ 12. Rio de Janeiro: PANAFTOSA-VP/ OPA/OMS; 2009.

10. Ministério da Saúde. Secretaria de Vigilância em Saúde. Consenso Brasileiro em Doença de Chagas. Rev Soc Bras Med Trop 2005; 38 (supl III):1-29.

11. Organización Panamericana de la Salud. Colóquio Internacional sobre la Enfermedad de Chagas Congénita. Rev Soc Bras Med Trop 2005; 38 (supl.II):1-124

12. Carlier Y, Torrico F. Infección congênita por Trypanosoma cruzi: desde los mecanismos de transmisión hasta las estratégias de diagnóstico y control. Rev Soc Bras Med Trop 2005; 38 (supl II): 114-118.

13. Luqueti AO, Rassi A. Diagnóstico laboratorial da infecção pelo Trypanosoma cruzi. In: Brener Z, Andrade ZA, Barral-Neto M, editores. Trypanosoma cruzi e doença de Chagas. Rio de Janeiro: Guanabara Koogan; 2000. p. 345-376.

14. Brener Z, Alquezar AS, Luqueti A. Normas de segurança para infecções acidentais com Trypanosoma cruzi, agente causador da doença de Chagas. Rev Patol Trop $1997 ; 26: 129-130$
15. Brener Z. Laboratory aquired Chagas' disease: endemic among parassitologists? In: Morel CM, editor. Genes and antigens of parasites: a laboratory manual. $2^{a}$ ed. Rio de Janeiro: Fundação Oswaldo Cruz; 1954. p.3-9.

16. Dias JCP. Mecanismos de transmissão. In: Brener Z, Andrade ZA, editores. Trypanosoma cruzi e doença de Chagas. Rio de Janeiro: Guanabara Koogan. 1979; p.152-179.

17. Chocair PR, Sabbaga E, Amato Neto V, Shiroma M, Góes GM. Transplante de rim: nova modalidade de transmissão da doença de Chagas. Rev Inst Med Trop S Paulo 1981; 23:280-282.

18. Nóbrega AA, Garcia MH, Tatto E, Obara MT, Costa E, Sobel J, et al Oral transmission of Chagas disease by consumption of açaí palm fruit Brazil. Em Infect Dis 2009; 15:653-655.

19. Shikanai-Yasuda MA, Brisola Marcondes C, Guedes LA, Siqueira GS, Barone AA, Dias JCP, et al. Possible oral transmission of acute Chagas' disease in Brasil. Rev Inst Med Trop S Paulo 1991; 33:351-357.

20. Silva NN, Clausell DT, Nólibos H, Mello AL, Ossanai J, Rapone T, et al. Surto epidêmico de doença de Chagas com provável contaminação oral. Rev Inst Med Trop S Paulo 1968; 10:265-276.

21. Marcili A, Valente VC, Valente AS, Junqueira ACV, Silva FM, Pinto AYN et al. Trypanosoma cruzi in Brazilian Amazon: lineages TCI and TCIIa in wild primates, Rhodinus spp, and in human with Chagas disease associated with oral transmission. Int J Parasitol 2009; 39: 615-623.

22. Pinto AYN, Ferreira Jr AG, Valente VC, Harada GS, Valente AS. Urban outbreak of acute Chagas disease in Amazon region of Brazil; four-year follow-up after treatment with benznidazole. Rev Panam Salud Publica 2009; 25:77-83.

23. Pinto AYN, Valente SA, Valente VC, Ferreira Jr AG, Coura JR. Fase aguda da doença de Chagas na Amazônia brasileira. Estudo de 233 casos do Pará, Amapá e Maranhão, observados entre 1988 e 2005. Rev Soc Bras Med Trop 2008; 41:602-614

24. Valente SAS, Valente VC, Pinto AYN, Cesar MJB, Santos MP, Miranda COS, et al. Analysis of an acute Chagas disease outbreak in the Brazilian Amazon human cases, triatomines, reservoir mammals and parasites. Trans $\mathrm{R}$ Soc Trop Med Hyg 2009; 103:291-297.

25. Deane MP, Lenzi HL, Jansen AM. Trypanosoma cruzi: vertebrate and invertebrate cycles in the same mammal host, the opossum Didelphis marsupialis. Mem Inst Oswaldo Cruz 1984; 79:513-515. 